\title{
The role of candle wax as non-bituminous modifier in material re- characterization of bituminous concretes used synonymously for flexible pavement- study on voids and flow
}

\author{
Enwuso A. Igwe, Captain G. Ottos \& Emmanuel O. Ekwulo \\ Department of Civil Engineering, Rivers State University of Science and Technology, Nkpolu Oroworukwo, \\ P.M.B 5080, 5080, Port Harcourt, Rivers State, Nigeria
}

\begin{abstract}
Improving the performance of flexible road pavements has been one of the major concerns in highway engineering, due mainly to the twin problems of temperature and oxidation that impede its performance. For instance at very high temperatures the binder (i.e. asphalt) in the concrete will become too soft and tend to separate from the pavement therefore becomes fluid and ready to flow under traffic loads. On the other hand when there is excessive oxidation the pavement suffers from air entrainment in the pores of the concrete thereby creating voids (i.e. air voids and VMA) beyond allowable limits. These parameters are actually major determinants in the stiffness and strains that control fatigue life of the pavement during its useful life. The present study sought measures of reducing these parameters such that the overall life of the pavement can be enhanced. On this basis candle wax was used to re-characterize asphalt concretes used synonymously to symbolize flexible pavement with a focus of modifying voids and flow properties. Results revealed that air voids was reduced by $22.7 \%, 16.7 \%$ and $16.7 \%$ for light, medium and heavy traffic respectively. Also VMA was reduced by $48 \%, 39.7 \%$ and $53.4 \%$ for light, medium and heavy traffic respectively. Finally, flow was reduced by $27.3 \%, 22.2 \%$ and $13.7 \%$ for light, medium and heavy traffic respectively.
\end{abstract}

Keywords: Material Characterization, Bituminous Concrete, Candle Wax, Voids and Flow

\section{Introduction}

The importance of characterization of pavement materials is that it helps the engineer to know whether or not a material will be suitable to achieve desired results in terms of performance during the design period. The philosophy behind re-characterization of pavement materials stems from the fact that most times the individual materials that make up a pavement structure falls short of required standards and stipulations. In effect when designs are carried out - such as mix design and structural designs the pavement performance is likely to fall short of desired expectations. This has led to deliberate efforts to either improve the properties of the individual components of the pavement structure or the pavement structure itself as a conglomerate; thus the introduction of modifiers and additives to help remedy such malady. This remediation process is what is likely to resemble re-characterization of pavement materials. The idea is to boost the overall performance of the pavement structure during its useful life.

With respect to the present study voids in asphalt concrete mixtures refer to those Mix Design properties that define the quantity of air and volume of mineral aggregate inside a given bituminous concrete mix. In practical reality it will mean the amount of air voids and mineral volume of aggregate particles that are inside of a pavement structure. On the other hand the flow property controls the movement or motion of the asphalt cement under temperature and loading conditions. When these conditions are satisfied it is likely that the pavement will meet design specifications. It is pertinent to state hear that in mix design the property of the asphalt concrete is categorized into five namely - Stability, Density, Flow, Air Voids and Voids in Mineral Aggregate. These mix design properties are further sub-divided into three categories as follows;

1. Strength Properties - Stability and Density

2. Flow Properties - Flow

3. Voids Properties - Air Voids and Voids in Mineral Aggregates

As earlier explained the voids property defines the quantity of air and volume of mineral aggregate inside a given bituminous concrete mix, whereas the flow property controls the movement or motion of the asphalt cement under temperature changes. In tropical regions, intense temperature rise can cause bleeding or flushing of the asphalt cement on the pavement. Research has shown that, the voids properties of bituminous concrete control the strength property of the concrete namely - density and stability. These in turn ultimately defines the pavement stiffness and strains that control the pavement response and behaviour with respect to fatigue life during the design life of the pavement (Igwe and Ekwulo, 2011; Igwe, 2014; Igwe, 2015 $5^{\mathrm{a}}$; Igwe, $2015^{\mathrm{b}}$ and Igwe, $2015^{\mathrm{c}}$ ). 
With respect to the present study our focus was directed towards the role and impact that Candle Wax as a non - bituminous modifier will have during the characterization of bituminous concrete with respect to Voids - air voids and voids in mineral aggregate (VMA) and flow of the concrete which are very important parameters that control pavement performance. Lastly, the term non-bituminous material refers to such material from bitumen cannot be derived in contrast to bituminous material referring to those from which bitumen can be derived.

\section{Literature}

Various researchers have focused on modifications of asphalt concrete mixtures using other additives and modifiers. The study by Flynn (1993) revealed that recycled polyethylene from grocery bags proved useful in asphaltic (bituminous) pavements resulting in reduced permanent deformation in the form of rutting and reduced low -temperature cracking of the pavement surface. The corollary of his finding posits that pavement performance and life can be enhanced by the use of additives (modifiers).

Buttressing the study by Flynn, Zoorob (2000), Zoorob and Suparma (2000) showed that recycled plastics composed predominantly of polypropylene and low density polyethylene can be incorporated into conventional asphaltic or bituminous road surfacing mixtures. Their separate studies revealed that the addition of recycled plastics resulted in greater durability and fatigue life in the modified mixes as compared to the conventional mixes. However, previous studies by Collins and Ciesielski (1993), and Federal Highway Administration (1993) revealed that the inclusion of these plastic materials in re-cycled form caused changes in the behaviour of asphalt concrete mixtures. Khan et al (1999) also strengthens the findings of Flynn, in the use of waste plastics as already discussed. They studied the effects of using waste plastics in asphalting roads and concluded that the incorporation of plastics into bituminous mixtures (concrete mixes) improved the performance of the pavement in terms of stability and fatigue life and other desirable properties of the pavement.

In the same line of research, Punith (2001) carried out laboratory studies at the centre for Transportation Engineering of Bangalore University on the use of processed plastic bags as an additive in bituminous concrete mixes. The findings of his research revealed that the properties of the modified bitumen were better than those of the unmodified. In addition, it was observed that penetration and ductility of the modified bitumen decreased with the increase in the proportion of the plastic added (that is 12 percent by weight of addition of plastic). In the same study the results further revealed that the softening point of the modified bitumen increased with the addition of plastic by up to 8 percent by weight. Further studies on the bituminous concrete mixes using 80/100 grade bitumen revealed that an average Marshall stability value of $1100 \mathrm{~kg}$ at optimum bitumen content of 5 percent by weight of the mix was obtained. However results of the plastic modified bituminous concrete mix using the same grade of bitumen fulfilled the Marshall Design criteria and also had an optimum binder content of 5 percent by weight of mix consisting of 8 percent by weight of processed plastic. The research findings on the modified bituminous concrete showed that the average Marshall stability value was $3312 \mathrm{~kg}$ at the optimum binder content resulting in about 3 times increase in the stability of the bituminous concrete mix containing 4.6 percent bitumen plus 8 percent processed plastic. From the general findings of the research Punith concluded that the advantages of using plastic modified bitumen substantially improved the stability or strength of the pavement. Other additives used as a bituminous modifier is the addition of blast furnace slag. The separate studies of Solomon (1992) and Sakai (1992) revealed that blast furnace slag consisting primarily of silicates and alumino -silicates of lime and other bases obtained as a by -product of iron in the form of blast furnace cement produced equal or improved performance over conventional Portland cement concrete during use in road constructions. The study of Sakai further revealed that the slag cement had low heat of hydration, good long-term strength gain and high chemical resistance.

Lastly, the study by Igwe et al (2009) on the use of rubber latex to modify asphalt concrete mixtures revealed that the mix design properties of the rubberized concrete produced better performance in terms of strength, voids and flow properties.

\subsection{Sample collection}

\section{Materials and Methods}

The materials used for this study were waste candle wax, asphalt, coarse and fine aggregates. The candle wax used were obtained as wastes from domestic use of candles while the aggregates used were obtained from market dealers at Mile 3 Diobu, in Port Harcourt City Local Government Area of Rivers State, Nigeria. On the other hand the asphalt used was collected from a private asphalt plant company $\mathrm{H} \& \mathrm{H}$ situated at Mbiama, in Ahoada West Local Government Area of Rivers State, Nigeria. After sampling of the materials, laboratory tests - specific gravity, grading of asphalt and sieve analysis of the aggregates used for mix-proportioning by straight line method - were carried out. 


\subsection{Sample Preparation}

Samples were prepared using Marshal Design Procedures for asphalt concrete mixes as presented in Asphalt Institute (1956), National Asphalt Pavement Association (1982) and Roberts et al (1996). The procedures involved the preparation of a series of test specimens for a range of asphalt (bitumen) contents such that test data curves showed well defined optimum values. Tests were scheduled on the bases of 0.5 percent increments of asphalt content with at least 3-asphalt contents above and below the optimum asphalt content. In order to provide adequate data, three replicate test specimens were prepared for each set of asphalt content used. During the preparation of the unmodified asphalt concrete samples, the aggregates were first heated for about 5 minutes before asphalt was added to allow for absorption into the aggregates. After which the mix was poured into a mould and compacted on both faces with 75 blows using a $6.5 \mathrm{~kg}$-rammer falling freely from a height of $450 \mathrm{~mm}$. Compacted specimens were subjected to bulk specific gravity test, stability and flow, density and voids analyses at a temperature of $60^{\circ} \mathrm{C}$ and frequencies of 1,5 , and $10 \mathrm{~Hz}$ respectively as specified by AASHTO Design Guide (2002). The results obtained were used to determine the optimum asphalt content of the unmodified asphalt concrete. Candle wax content were then added at varying amounts $(5-25$ percent by weight of the asphalt at optimum) to the samples at optimum asphalt content and then re-designed using the same Marshal Design Procedures already stated above to produce candle wax modified concretes having varying mix design properties.

\subsection{Theory}

The optimum asphalt content (O.A.C.) for the unmodified bituminous concrete was obtained using equation 1, according to the Marshal Design Procedure cited in (Asphalt Institute, 1956; National Asphalt Pavement Association, 1982) as follows:

O.A.C. $=\frac{1}{3}\left(A \cdot C_{r_{\text {max. }} \text { stability }}+A \cdot C_{r_{\text {max. density }}}+A \cdot C_{r_{\text {median limits of air voids }}}\right)$

IV. Results (See Tables 1 - 4 \& Figures 1 - 7)

Table 1: Laboratory test results of stated materials

\begin{tabular}{|l|l|l|l|l|}
\hline Material & Candle Wax & Asphalt & Sand & Gravel \\
\hline Specific gravity & 0.80 & 1.05 & 2.52 & 2.86 \\
\hline Grade of binder material & - & $40 / 50$ & - & - \\
\hline Mix proportion (\%) & - & - & 41 & 59 \\
Viscosity of binder (poise) & - & $1.45^{*}\left(10^{-6}\right)$ & - & - \\
Softening point & - & $50^{\circ} \mathrm{C}$ & - & - \\
Penetration value & - & $53 \mathrm{~mm}$ & - & - \\
\hline
\end{tabular}

Table 2: Schedule of Aggregates Used For Mix Proportion in Accordance With ASTM 1951: C136

\begin{tabular}{|l|l|l|l|l|}
\hline $\begin{array}{l}\text { Sieve size } \\
(\mathbf{m m})\end{array}$ & $\begin{array}{l}\text { Specification } \\
\text { limit }\end{array}$ & $\begin{array}{l}\text { Aggregate A } \\
\text { (Gravel) }\end{array}$ & $\begin{array}{l}\text { Aggregate B } \\
(\text { Sand) }\end{array}$ & $\begin{array}{l}\text { Mix proportion } \\
(\mathbf{0 . 5 9 A + 0 . 4 1 B})\end{array}$ \\
\hline 19.0 & 100 & 99.1 & 100 & 99.45 \\
\hline 12.5 & $86-100$ & 86.1 & 100 & 91.80 \\
\hline 9.5 & $70-90$ & 57.5 & 100 & 74.93 \\
\hline 6.3 & $45-70$ & 21.8 & 100 & 53.86 \\
\hline 4.75 & $40-60$ & 7.5 & 99.5 & 45.22 \\
\hline 2.36 & $30-52$ & 3.5 & 97.3 & 41.96 \\
\hline 1.18 & $22-40$ & 2.3 & 92.3 & 39.20 \\
\hline 0.6 & $16-30$ & 1.8 & 69 & 29.30 \\
\hline 0.3 & $9-19$ & 1.4 & 28.2 & 12.39 \\
\hline 0.15 & $3-7$ & 1 & 8.4 & 4.0 \\
\hline 0.075 & 0 & 0.6 & 0.8 & 0.68 \\
\hline
\end{tabular}

Table 3: Summary of Mix Design Properties for Unmodified Concrete for the Three Categories of Traffic

\begin{tabular}{|c|c|c|c|c|c|c|}
\hline $\begin{array}{l}\text { Asphalt Content } \\
\text { (\%) }\end{array}$ & Traffic category & Stability (N) & Flow $(0.25 \mathrm{~mm})$ & Density $\left(\mathrm{kg} / \mathrm{m}^{3}\right)$ & Air voids (\%) & VMA (\%) \\
\hline \multirow{3}{*}{4.0} & Light & 2236 & 11.80 & 2050 & 4.90 & 28.80 \\
\hline & Medium & 3680 & 10.40 & 2180 & 4.50 & 26.81 \\
\hline & Heavy & 6690 & 9.50 & 2210 & 4.10 & 22.76 \\
\hline \multirow{3}{*}{4.5} & Light & 3060 & 13.20 & 2240 & 4.30 & 22.10 \\
\hline & Medium & 4660 & 11.70 & 2250 & 4.00 & 21.75 \\
\hline & Heavy & 8400 & 10.30 & 2270 & 3.70 & 21.05 \\
\hline \multirow{4}{*}{5.0} & Light & 3270 & 15.00 & 2260 & 3.90 & 21.78 \\
\hline & Medium & 5220 & 13.10 & 2270 & 3.60 & 21.44 \\
\hline & Heavy & 8960 & 11.60 & 2280 & 3.40 & 21.10 \\
\hline & Light & 2870 & 17.30 & 2120 & 3.60 & 26.20 \\
\hline
\end{tabular}


The role of candle wax as non-bituminous modifier in material re-characterization ...

\begin{tabular}{|l|l|l|l|l|l|l|}
\hline 5.5 & Medium & 4710 & 15.00 & 2150 & 3.40 & 25.45 \\
\cline { 2 - 7 } & & & & & & \\
\cline { 2 - 7 } & Heavy & 7990 & 13.40 & 2220 & 3.20 & 23.88 \\
\hline \multirow{3}{*}{6.0} & Light & 2310 & 19.95 & 2071 & 3.50 & 29.80 \\
\cline { 2 - 7 } & Medium & 3720 & 17.30 & 2092 & 3.30 & 28.60 \\
\cline { 2 - 7 } & Heavy & 6750 & 15.40 & 2125 & 3.10 & 27.48 \\
\hline
\end{tabular}

Table 3 above shows the results of the mix design properties of the unmodified asphalt concrete for the different categories of traffic.

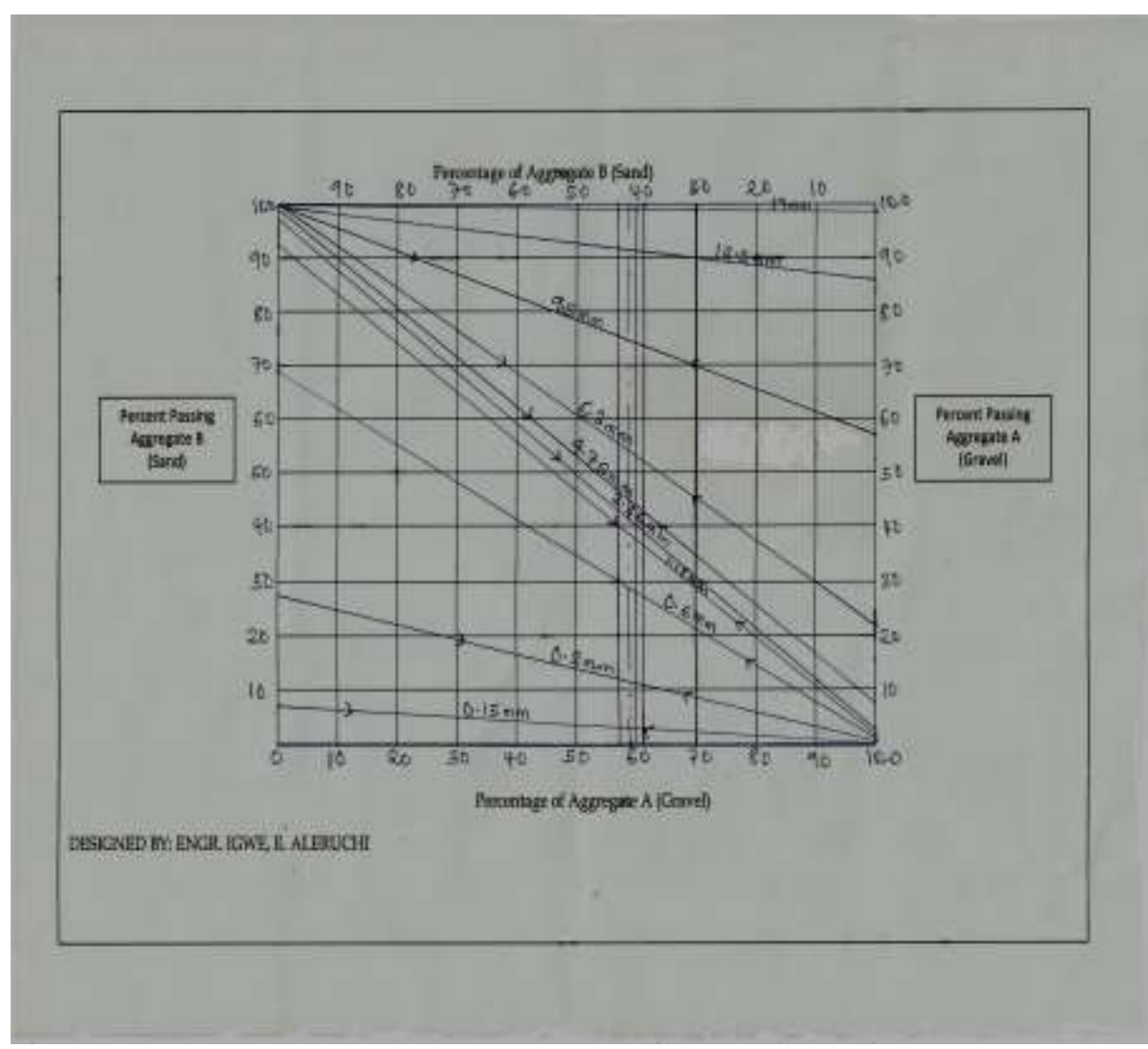

Figure 1: Blending of Aggregates by Straight Line Method

\section{Analysis}

1. Plot a graph of each design property against asphalt content: that is, a graph of the following:

- Stability against asphalt content

- Density against asphalt content

- Air voids against asphalt content

2. Determine the following parameters:

- Asphalt content at maximum stability (x)

- Asphalt content at maximum density (y)

- Asphalt content at median limits of air voids (i.e. at $4 \%$ air voids) (z)

3. Determine their arithmetic average asphalt content which is equal to the design asphalt content or optimum asphalt content of concrete (O.A.C). That is,

4. $O \cdot A \cdot C=1 / 3(x+y+z)$ from equation 1 above

5. Obtain mix design properties for each traffic category at optimum asphalt content.

6. Check for suitability of design parameters with Marshal Standards

In order to determine the optimum asphalt content (i.e. design asphalt content) for the 3 categories of traffic; Equation 1 was applied in line with figures 2, 3 and 4 respectively as already outlined above. Results obtained revealed that the optimum asphalt contents obtained were $4.9 \%, 4.8 \%$ and $4.6 \%$ for light, medium and heavy traffic categories respectively. 


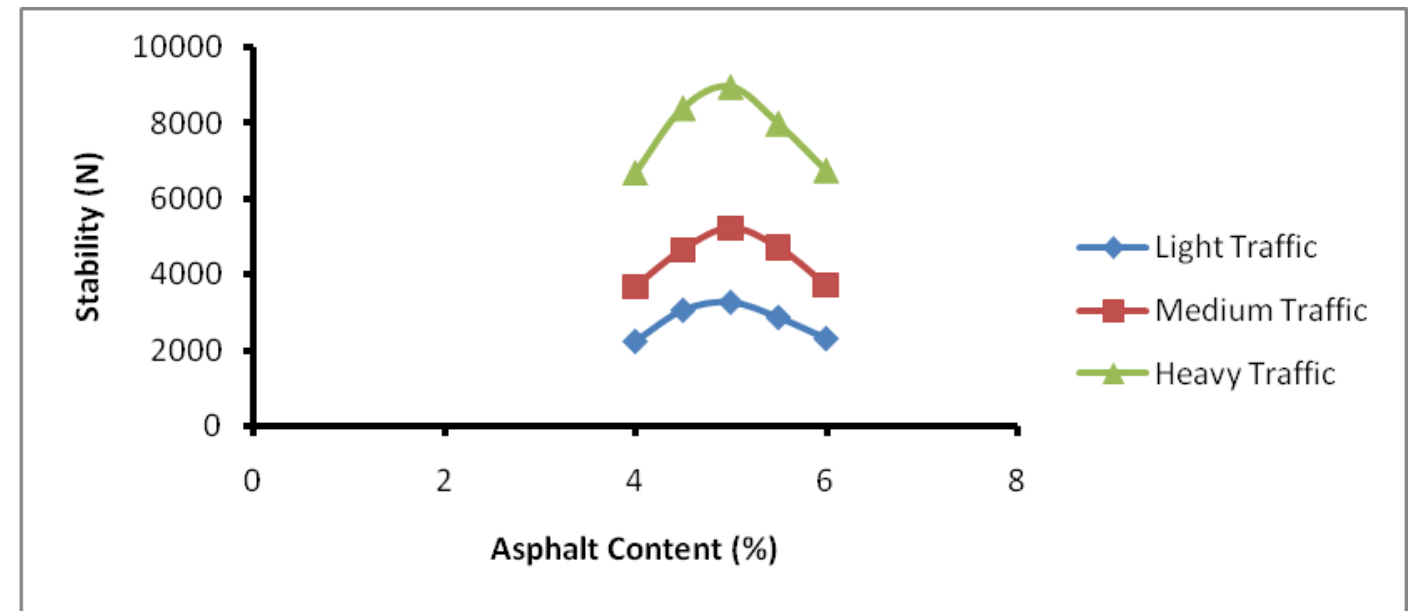

Figure 2: Stability against Asphalt content

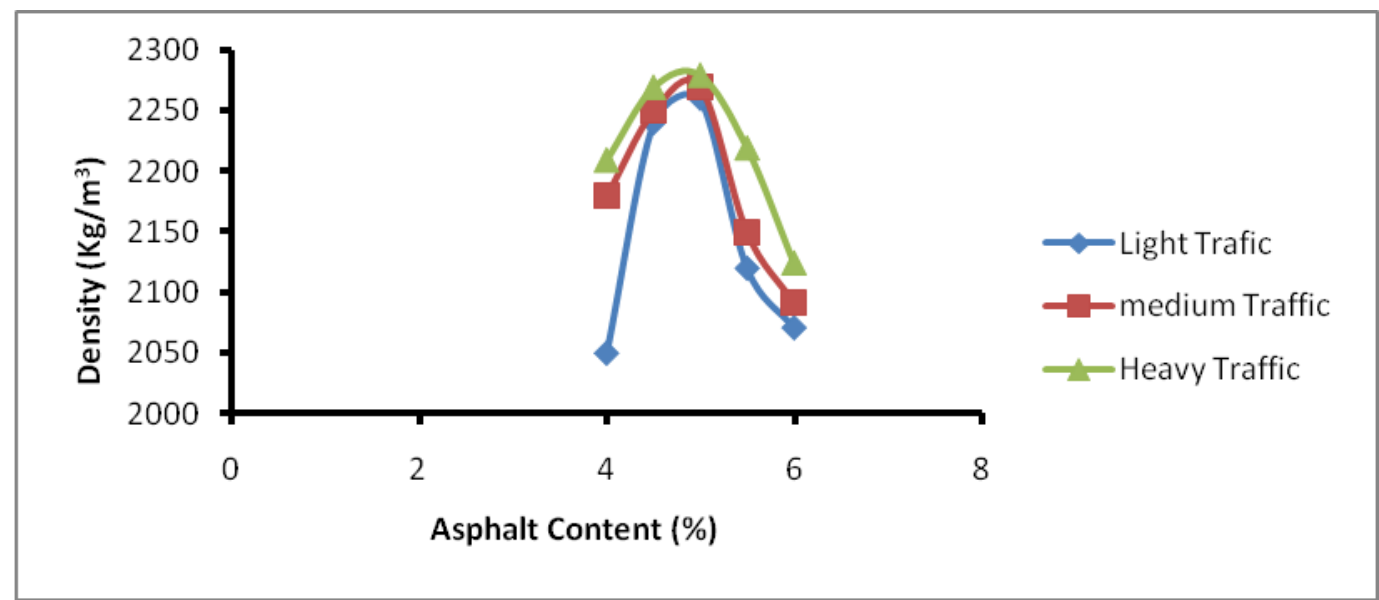

Figure 3: Density against Asphalt content

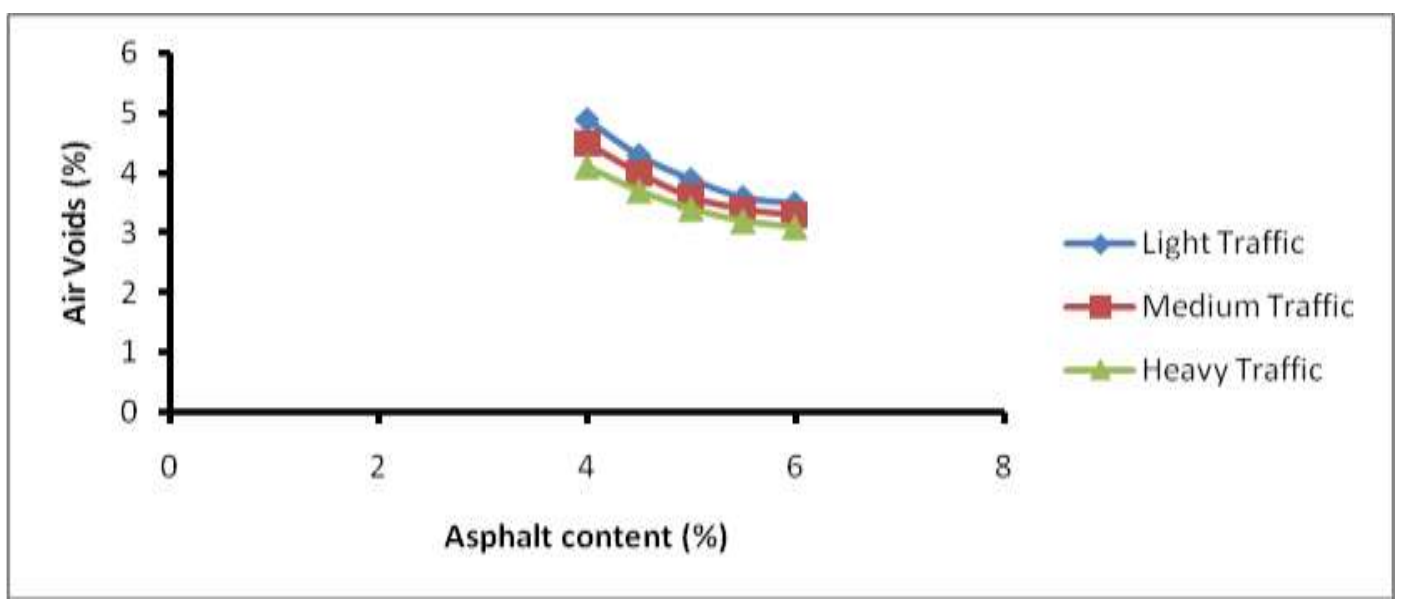

Figure 4: Air Voids against Asphalt content

Table 4: Summary of Mix Design Properties for Candle Wax modified Bituminous Concrete for the Three Categories of Traffic with respect to Voids and Flow at Optimum asphalt Contents

\begin{tabular}{|l|l|l|l|l|}
\hline Candle Wax Content (\%) & Traffic category & Flow $(0.25 \mathrm{~mm})$ & Air voids (\%) & VMA (\%) \\
\hline \multirow{3}{*}{0} & Light & 14.64 & 4.4 & 22 \\
\cline { 2 - 5 } & Medium & 12.54 & 3.7 & 20.69 \\
\cline { 2 - 5 } & Heavy & 10.56 & 3.6 & 21.15 \\
\hline \multirow{3}{*}{5} & Light & 12.42 & 4.0 & 16.9 \\
\cline { 2 - 5 } & Medium & 11.64 & 3.6 & 16.10 \\
\cline { 2 - 5 } & Heavy & 10.00 & 3.6 & 14.82 \\
\hline
\end{tabular}


The role of candle wax as non-bituminous modifier in material re-characterization ...

\begin{tabular}{|l|l|l|l|l|}
\hline \multirow{3}{*}{10} & Light & 11.24 & 3.8 & 12.99 \\
\cline { 2 - 5 } & Medium & 10.34 & 3.4 & 14.14 \\
\cline { 2 - 5 } & Heavy & 9.63 & 3.3 & 10.76 \\
\hline \multirow{3}{*}{20} & Light & 10.64 & 3.4 & 11.37 \\
\cline { 2 - 5 } & Medium & 9.76 & 3.1 & 12.48 \\
\cline { 2 - 5 } & Heavy & 9.11 & 3.0 & 9.86 \\
\hline \multirow{3}{*}{25} & Light & 11.75 & 3.9 & 16.43 \\
\cline { 2 - 5 } & Medium & 11.32 & 3.5 & 15.98 \\
\cline { 2 - 5 } & Heavy & 9.76 & 3.0 & 11.74 \\
\hline & Light & 12.54 & 4.2 & 21.74 \\
\cline { 2 - 5 } & Medium & 12.64 & 4.0 & 21.20 \\
\cline { 2 - 5 } & Heavy & 10.60 & 3.7 & 15.63 \\
\hline
\end{tabular}

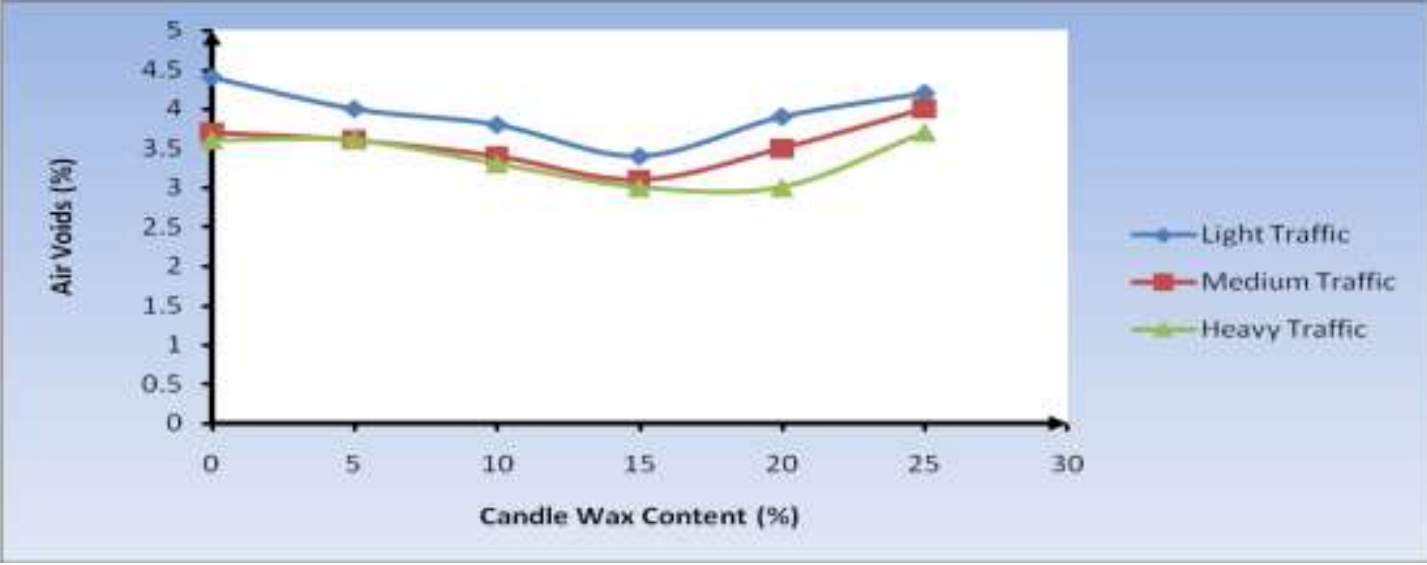

Figure 5: Air Voids variation with Candle Wax content

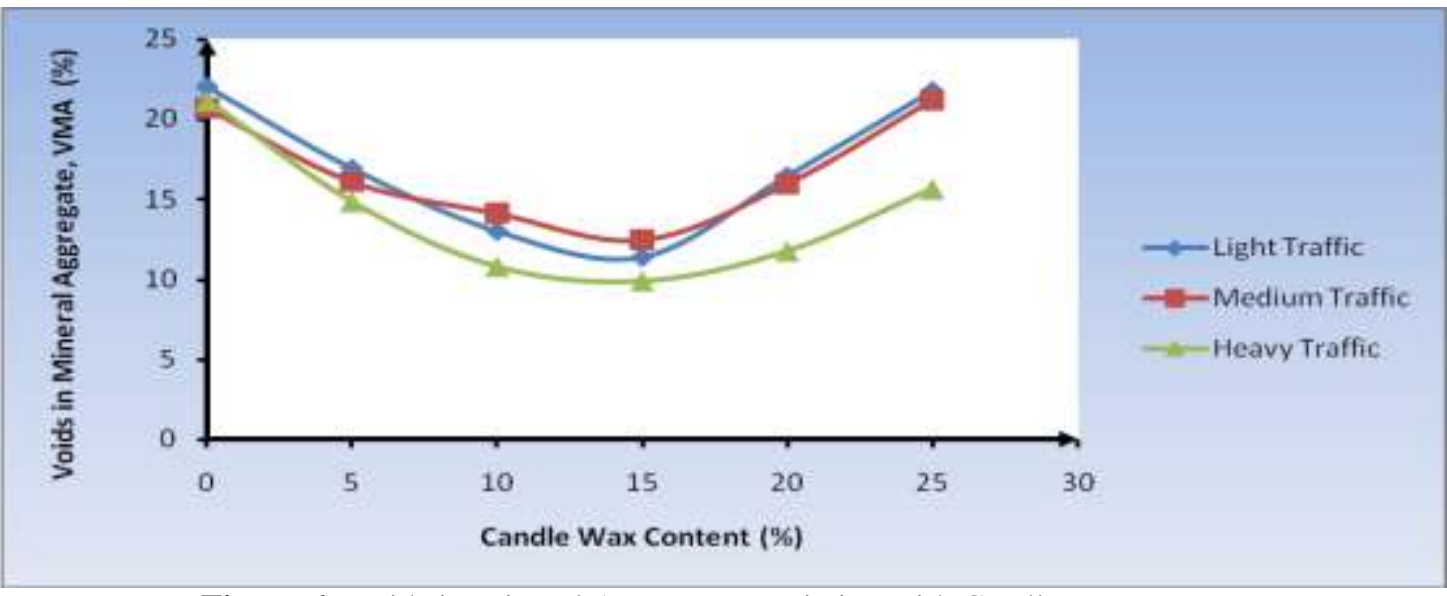

Figure 6: Voids in Mineral Aggregates variation with Candle Wax content

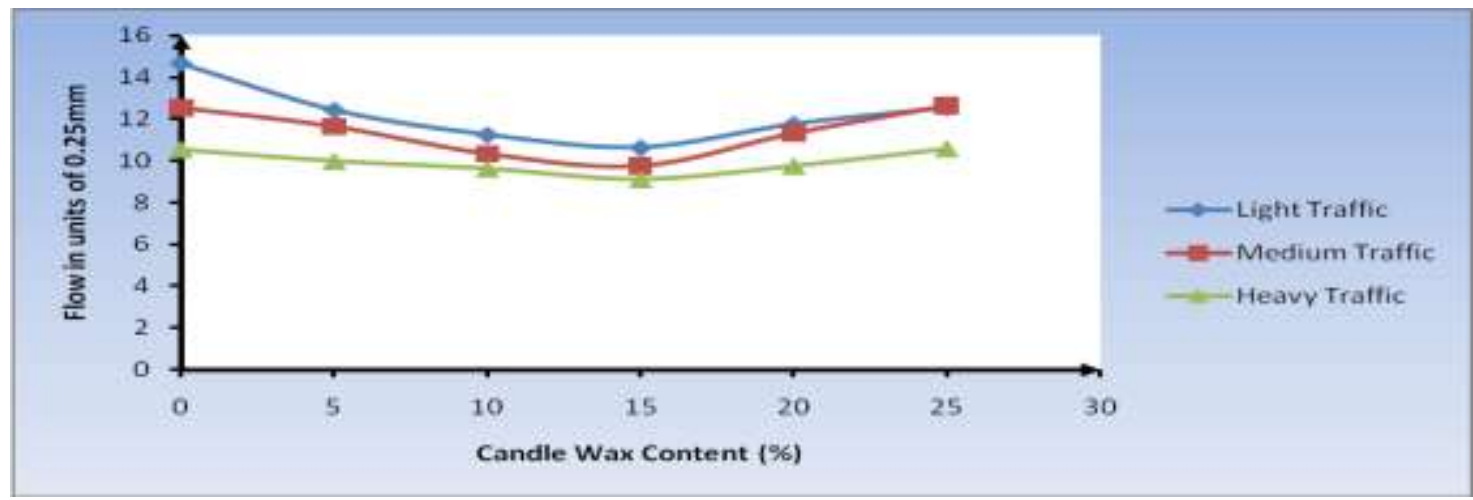

Figure 7: Flow variation with Candle Wax content 


\section{Discussions}

The results of air voids, VMA and flow variations with respect to varying candle wax content is presented in Table 4 and Figures 5-7 above for each traffic category.

\section{a. Air Voids}

From figure 5 it was observed that the air voids content of the asphalt concretes for light traffic decreased from $4.4 \%$ at $0 \%$ candle wax content to $3.4 \%$ at $15 \%$ candle wax content. Also from figure 5 the results revealed that air voids content of the asphalt concretes for medium traffic decreased from $3.7 \%$ at $0 \%$ candle wax content to $3.1 \%$ at $15 \%$ candle wax content. Finally, figure 5 further revealed that the air voids content of the asphalt concretes for heavy traffic category reduced from $3.6 \%$ at $0 \%$ candle wax content to $3 \%$ at $15 \%$ candle wax content.

\section{b. Voids in Mineral Aggregate - VMA}

From figure 6 it was observed that the VMA of the asphalt concretes for light traffic decreased from $22 \%$ at $0 \%$ candle wax content to $11.3 \%$ at $15 \%$ candle wax content. Also from figure 6 the results revealed that VMA of the asphalt concretes for medium traffic decreased from $20.69 \%$ at $0 \%$ candle wax content to $12.48 \%$ at $15 \%$ candle wax content. Finally, figure 6 further revealed that the VMA of the asphalt concretes for heavy traffic category reduced from $21.15 \%$ at $0 \%$ candle wax content to $9.86 \%$ at $15 \%$ candle wax content.

\section{c. Flow}

From figure 7 it was observed that the flow of the asphalt concretes for light traffic decreased from $14.64 \%$ at $0 \%$ candle wax content to $10.64 \%$ at $15 \%$ candle wax content. Also from figure 7 the results revealed that VMA of the asphalt concretes for medium traffic decreased from $12.54 \%$ at $0 \%$ candle wax content to $9.76 \%$ at $15 \%$ candle wax content. Finally, figure 7 further revealed that the VMA of the asphalt concretes for heavy traffic category reduced from $10.56 \%$ at $0 \%$ candle wax content to $9.11 \%$ at $15 \%$ candle wax content.

\section{Conclusion}

From the laboratory test results obtained including analysis made the following conclusions are drawn;

i. That candle wax addition contributed significantly to reduction of air voids in the asphalt concrete mixtures for all traffic categories $-22.7 \%, 16.7 \%$ and $16.7 \%$ for light, medium and heavy traffic respectively

ii. That candle wax addition contributed significantly to reduction of VMA in the asphalt concrete mixtures for all traffic categories $-48 \%, 39.7 \%$ and $53.4 \%$ for light, medium and heavy traffic respectively

iii. That candle wax addition contributed significantly to reduction of flow in the asphalt concrete mixtures for all traffic categories $-27.3 \%, 22.2 \%$ and $13.7 \%$ for light, medium and heavy traffic respectively

\section{References}

[1] AASHTO Design Guide Draft (2002) - 2.4 Modulus of Elasticity for Major Material Groups, NCHRP Project 1-37A

[2] Asphalt Institute (1956) 'Mix Design methods for Hot-mix Asphalt Paving', University of Maryland, Manual Series No.2. Lexington.

[3] Collins, R. J. and Ciesielski, S. K. (1993) 'Recycling of Waste Materials and by Products in Highway Construction', (1 \& 2); Office of Research and Development, U.S. Federal Highway Administration. Washington, DC.

[4] Federal Highway Administration, (1993) 'Engineering and Environmental Aspects of Recycled Materials for Highway Construction', (1): Final Report FHWA Contract No. DTFH61-92-COO60, Washington DC.

[5] Flynn, L. (1993) 'Recycled Plastic Finds Home in Asphalt Binder', Journal of Roads and Bridges. (58)2; 32 - 41.

[6] Igwe, E. A.; Ayotamuno, M. J.; Okparanma, R. N.; Ogaji, S. O. T.; and Probert, S. D. (2009) 'Road Surface Properties affecting Rates of Energy Dissipation from Vehicles' Journal of Applied Energy, vol. 86, pp. 1692-1696, Elsevier Publishing.

[7] Igwe, E. A., and Ekwulo, E.O. (2011). Influence of Rubber Latex on Dynamic Modulusof Hot Mix Asphalt Concrete (2011) "Archives of Applied Science Research Scholars Research Library", Vol.3, No.4, pp. 319-327. Available Online at www.scholarsresearchlibrary.com

[8] Igwe, E. A. (2014). Increasing Axle Load Repetitions $\left(\mathrm{N}_{\mathrm{f}}\right)$ Causing Fatigue Failure in Highway Flexible Pavements through Rubberization: Light Traffic Study“"Global Advanced Research Journal of Engineering, Technology and Innovation” (ISSN: 23155124) Vol. 3(4) pp. 077-082, June, 2014. Available online at http://garj.org/garjeti/index.htm Copyright (C) 2014 Global Advanced Research Journals

[9] Igwe, E. A. (2015 $)$ Fatigue Life Extension in HMA Concretes through the Inclusion of Candle Wax as Modifier for Heavy Trafficked Pavement "Global Advanced Research Journal of Engineering, Technology and Innovation" (ISSN: 2315- 5124) Vol. 4(7) pp. 86-091, September, 2015. Available online at http://garj.org/garjeti/index.htm Copyright (C) 2015 Global Advanced Research Journals

[10] Igwe, E. A. $\left(2015^{\mathrm{b}}\right)$. Influence of Candle Wax on Stiffness of Hot Mix Asphalt Concrete: Light Traffic Case "Global Advanced Research Journal of Engineering, Technology and Innovation” (ISSN: 2315-5124) Vol. 4(7) pp. 098-104, September, 2015. Available online at http://garj.org/garjeti/index.htm Copyright @ 2015 Global Advanced Research Journals

[11] Igwe, E. A. $\left(2015^{\mathrm{c}}\right)$. Effects of Air Voids Variation on Stiffness Property of HMA Concretes Modified with Rubber Latex "International Journal of Emerging Trends in Engineering Research. September 2015, vol. 3, No.9, Issue: pp. 86-93. Available online@ http://www.warse.org/IJETER/static/pdf/file/ijeter02392015.pdf

[12] Khan, A., Mohan, M. and Raykar, V. (1999) 'Effective Utilization of Waste Plastics in Asphalting Roads'. Project Report, Department of Chemical Engineering, R.V.College of Engineering, Bangalore. India. 
[13] National Asphalt Pavement Association (1982) 'Development of Marshall Procedures for Designing Asphalt Paving Mixtures', National Asphalt Pavement Association, Information Series (84), Lanham, MD.

[14] Punith, V.S. (2001) 'Effect of plastic modifiers on bituminous mix properties', Seminar Report, II Semester in M.E. Highway Engineering, Department of Civil Engineering, Bangalore University, Bangalore, India.

[15] Roberts, F.L. Kandhal, P.S., Brown, E.R., Lee, D.Y. and Kennedy, T.W. (1996). Hot-Mix Asphalt Materials, Mixture Design, and Construction. National Asphalt Pavement Association Education Foundation Lanham, MD.

[16] Sakai, K. (1992) 'Properties of Granulated Blast-Furnace slag Cement Concrete' Proceedings of the Fourth International Conference on fly ash, silica fume, slag and Natural Pozzolans in Concrete, Istanbul, Turkey.

[17] Solomon, C. (1992) "Slag Iron and Steel", Annual Report, U.S. Department of the Interlor, Bureau of Mines, Washington, D.C.

[18] Zoorob, S.E. (2000) 'Laboratory Design and Performance of Improved Bituminous Composites Utilizing Plastics Packaging Waste'. Conference on Technology Watch and Innovation in Construction Industry. Building Research Institute, Brussels, Belgium (April, 2000)

[19] Zoorob, S.E. and Suparma, L.B. (2000) "Laboratory Design and Investigation of proportion of bituminous composite containing waste recycled plastics aggregate replacement (Plastiphalt), CIB Symposium on Construction and Environment: Theory into practice. Sao Paulo, Brazil. (November, 2000). 